\title{
Immunobiology
}

Immunobiology 214 (2009) 703-711

www.elsevier.de/imbio

\section{A continuous infusion of a minor histocompatibility antigen-immunodominant peptide induces a delay of male skin graft rejection}

\author{
Guido Sireci $^{\mathrm{a}}$, Annalisa Barera ${ }^{\mathrm{a}}$, Pasquale Macaluso ${ }^{\mathrm{a}}$, Caterina Di Sano ${ }^{\mathrm{b}}$, Cesira \\ T. Bonanno ${ }^{a}$, Marco Pio La Manna ${ }^{\mathrm{a}}$, Diana Di Liberto ${ }^{\mathrm{a}}$, Francesco Dieli ${ }^{\mathrm{a}, \mathrm{b}}$, \\ Alfredo Salerno ${ }^{\mathrm{a}, \mathrm{b}, *}$ \\ ${ }^{a}$ Dipartimento di Biopatologia e Metodologie Biomediche, Università di Palermo, Corso Tukory 211, 90134 Palermo, Italy \\ ${ }^{\mathrm{b}}$ Istituto di Biomedicina e Immunologia Molecolare, Consiglio Nazionale delle Ricerche, Via Ugo La Malfa 153, \\ 90146 Palermo, Italy
}

Received 23 July 2008; received in revised form 9 December 2008; accepted 9 December 2008

\begin{abstract}
We previously reported that an inhibition of antigen-specific Interferon- $\gamma$ release and cytotoxicity occurs after a continuous infusion of an HY immunodominant peptide although this treatment is not able to cause a significant delay of male skin grafts rejection. In vivo administration of high doses of an HY peptide, through mini-osmotic pumps, in naïve female mice was used to study the effects on the male skin grafts rejection. A continuous infusion of $1 \mathrm{mg}$ of an HY peptide induces a significant delay of male skin graft rejection. In vitro HY-specific Interferon- $\gamma$ release was inhibited adding peptide-specific suppressor cells: the ability to inhibit Interferon- $\gamma$ release was evident when two HY peptides were present on the same dendritic cells indicating that the suppressor cells exert "linked-suppression". The phenotype of the suppressor cells is $\mathrm{CD} 8{ }^{+} \mathrm{CD} 28^{-}$and these cells express more CD62 ligand and FOXP3 than controls. Suppressor cells were able to cause a significant delay of rejection of male skin grafts when injected in naive female mice. The inhibitory effects of these suppressor cells seem to be due to the impairment of antigen presentation; downregulation of B7 molecules on dendritic cells occurred. Taken all together, our data demonstrate that a continuous infusion of an immunodominant HY peptide induces a T CD8 suppressor subset able to inhibit immune responses to male tissues and cells.
\end{abstract}

(C) 2009 Elsevier GmbH. All rights reserved.

Keywords: Antigen presentation; Minor histocompatibility antigens; Rodent; Skin grafting; Suppressor cells

Abbreviations: APC, antigen presenting cells; BMDC, bone marrow dendritic cells; CD40L, CD40 ligand; CD62L, CD62 ligand; CFSE, 5,6carboxy-2,7-dechlorofluorescein; FACS, fluorescence activated cell sorter; FCS, foetal calf serum; GMCSF, granulocyte monocyte colony stimulating factor; IFA, Incomplete freunds adjuvant; LN, lymph node; MFI, mean fluorescence intensity; PBS, phosphate buffered saline; SPT, soluble peptide by miniosmotic pump treated; TCR, T cell receptor.

*Corresponding author at: Dipartimento di Biopatologia e Metodologie Biomediche, Università di Palermo, Corso Tukory 211, 90100 Palermo, Italy. Tel.: + 39916555903 ; fax: + 39916555901

E-mail address: asalerno@unipa.it (A. Salerno). 


\section{Introduction}

The immune responses to minor histocompatibility antigens (minor H Ags) can be responsible for host-vsgraft $(\mathrm{HvG})$ rejection and graft-vs-host $(\mathrm{GvH})$ disease in MHC-matched human transplantation and in animal models (Simpson et al. 2002). Molecular identity of a number of human and mouse minor $\mathrm{H}$ Ags has been well elucidated (Simpson et al. 2002; Simpson and Roopenian, 1997). As indicated from the detailed genetic analysis of minor H Ags, polymorphic polypeptides can give rise, after their processing, to single peptides that associate with MHC class I and II molecules.

The HY minor $\mathrm{H}$ Ags are particularly subjected to analysis because all the epitopes are encoded by genes located on the Y chromosome, and in mice, these map to the $S x r$ deletion interval $(\Delta S x r)$ (Simpson et al. 1997).

MHC class I- and II-restricted HY epitopes of the H$2^{\mathrm{b}}$ haplotype have been identified (Greenfield et al. 1996; Markiewicz et al. 1998; Scott et al. 2000). The two MHC class I-restricted peptides, WMHHNMLDI (WI) and KCSRNRQYL (KL), originated, respectively, from the Uty and Simcy genes, associate with the $\mathrm{H}-2 \mathrm{D}^{\mathrm{b}}$ molecule. Some evidences suggest that the WI peptide is immunodominant because $\mathrm{T}$ cells with specificity for $\mathrm{H}-2 \mathrm{D}^{\mathrm{b}}$ / $\mathrm{KL}$ are less commonly isolated than $\mathrm{H}-2 \mathrm{D}^{\mathrm{b}} / \mathrm{WI}$ specific cells (Gavin et al. 1994). Further, transgenic mice expressing a TCR specific for the KL epitope fail to reject male skin grafts, suggesting that this receptor may have poor reactivity for HY epitopes (Bassiri et al. 1993).

We previously reported that the continuous delivery of soluble HY peptide WI by mini-osmotic pumps at the dose of $0.5 \mathrm{mg}$, led to a strong inhibition of antigenspecific cytotoxic activity, Interferon (IFN)- $\gamma$ production and to the priming of Interleukin (IL)-4 producing $\mathrm{CD}^{+} \mathrm{T}$ cells without significantly influencing the time course of male skin graft rejection (Sireci et al. 1999).

The aim of the present paper was to characterize the mechanism of hyporesponsiveness induced by the continuous infusion of the WI peptide. Here, we report that the administration of $1 \mathrm{mg}$ of peptide by miniosmotic pumps is able to delay significantly male skin graft rejection inducing antigen-specific suppressor cells.

\section{Materials and methods}

\section{Mice}

Mice of the C57BL/6 (H-2 ${ }^{\mathrm{b}}$, Thy1.2) strain were obtained from Nossan (Correzzana, Milan, Italy) while the Thy1.1 C57BL/6 congenic mice were obtained from The Jackson Laboratory (Bar Harbor, ME, USA). Mice were used at 8-12 weeks of age. Each experimental group consisted of 5-10 mice.

\section{Synthetic peptides, immunization and implantation of mini-osmotic pumps}

Sequences of the HY-D ${ }^{\mathrm{b}}$ peptides WMHHNMDLI (WI), KCSRNRQYL (KL) and C-terminal (350-369) 20 mer peptide of the $38 \mathrm{kDa}$ protein of Mycobacterium tuberculosis (p38G) with the sequence in brackets (DQVHFQPLPPAVVSKDSALI) were synthesized by Chem Progress, Milan, Italy. The peptides were of $90 \%$ purity and their homogeneity was confirmed by analytical reverse phase HPLC, mass spectrometry and amino acid composition analysis (Chem Progress, Milan, Italy).

Female mice were immunized through a subcutaneous injection into the hind footpads of $80 \mu \mathrm{g}$ of the peptide emulsified in incomplete Freund's adjuvant (IFA) (Difco Detroit, MI, USA). Control mice were treated with phosphate buffered saline (PBS). Mini-osmotic pumps (Alzet 2001, Alza Corp., Palo Alto, CA, USA) were implanted through a $5-\mathrm{mm}$ long transversal cut made in the skin of the lumbosacral region. Pump flow regulator pointed cranially. The wound was then closed with stitches. 0.5 or $1 \mathrm{mg}$ of WI peptide dissolved in $200 \mu \mathrm{l}$ of sterile PBS or PBS alone were aseptically injected in each mini-osmotic pump and the mean pumping rate was $1 \mu \mathrm{l} / \mathrm{h}$.

Popliteal lymph nodes (LN) were removed aseptically from mice immunized with a single subcutaneous injection of peptide dissolved in IFA 7 days after immunization. Axillary, inguinal LN and spleens were removed 7 days after implantation of pumps containing $1 \mathrm{mg}$ of WI peptide dissolved in PBS. Single cell suspensions were prepared in RPMI 1640 (Gibco, Grand Island, NY, USA) supplemented with $10 \%$ of Foetal Calf Serum (FCS) (Gibco), $2 \mathrm{mM}$ L-Glutamine (Gibco), $100 \mathrm{U} / \mathrm{ml}$ Penicillin/Streptomycin (Gibco), $5 \times 10^{-5}$ 2-Mercaptoethanol (Gibco) and $10 \mathrm{mM}$ HEPES (Gibco).

\section{Bone marrow cells}

Bone marrows cells were isolated from the femurs and tibias of donor mice. The bones were excised and cleaned of muscle and tendon and cut at the epiphysis at each end. Bone marrows were flushed out with $5 \mathrm{ml}$ of RPMI $/ 10 \%$ FCS, using a syringe with a 25 gauge needle. From total bone marrow cells, dendritic cells (DC) were obtained by plastic adherent fraction incubating bone marrow cells on FCS covered Petri dishes for $2 \mathrm{~h}$ at $37{ }^{\circ} \mathrm{C}$ in $5 \% \mathrm{CO}_{2}$ atmosphere. $5 \times 10^{5}$ $\mathrm{ml}$ of plastic adherent cells were cultured with $50 \mathrm{ng} / \mathrm{ml}$ rm granulocyte monocyte-colony stimulating factor 
GM-CSF (BD Bioscience, San Diego, CA, USA) and $10 \mathrm{ng} / \mathrm{ml} \mathrm{rmIL-4} \mathrm{(BD} \mathrm{Bioscience)} \mathrm{for} 7$ days. To promote maturation, cultures were passaged $24 \mathrm{~h}$ before harvesting in culture containing tumor necrosis factor (TNF)- $\alpha$. The majority of cells in these cultures were CD11c, CD80 and CD86 positive. Before the use, BMDC were irradiated by a Caesium source ( $30 \mathrm{~Gy}$ ). To analyze B7 expression, $2 \times 10^{5} / \mathrm{ml}$ mature BMDC, at day 7 of culture, were cultured with $6 \times 10^{5} / \mathrm{ml}$ $\mathrm{CD} 8{ }^{+} \mathrm{CD} 28^{-}$or $\mathrm{CD} 8^{+} \mathrm{CD} 28^{+}$cells. After $24 \mathrm{~h}$ of incubation, DC were recovered using anti mouse CD11c (Clone N418, hamster IgG, Serotec, Oxford, UK) microbeads (Miltenyi, Copenhagen, Denmark) and modulation of B7 expression was tested by CD80-FITC mAb (Clone RMMP-1, rat IgG2a, Serotec) and CD86FITC mAb (Clone MCA1587, rat IgG2a, Serotec, Oxford, UK) FACS analysis. For down-regulation experiments, data are expressed on gated living cells calculating by FACS software (Cell Quest) percentages and mean fluorescence intensity (MFI).

\section{IFN- $\gamma$ production}

$2 \times 10^{5} /$ well draining $\mathrm{LN}$ cells from mice injected with peptide emulsified in IFA were cultured in quadruplicate with $2 \times 10^{4} /$ well male APC in 96 -well microtitre plates (Nunc, Copenhagen, Denmark). In some experiments female APC at $2 \times 10^{5} /$ well were pulsed for $6 \mathrm{~h}$ at $37^{\circ} \mathrm{C}$ with $50 \mu \mathrm{g}$ of peptide. After washing $2 \times 10^{4} /$ well APCs were used to stimulate IFN- $\gamma$ production by LN cells from mice immunized with WI (responder cells). After $48 \mathrm{~h}$ of culture, supernatants were harvested and tested for IFN- $\gamma$ content. IFN- $\gamma$ was quantified by sandwich ELISA, using commercially available mAbs and protocols recommended by PharMingen Ltd. rmIFN- $\gamma$ obtained from PharMingen was used for standard curve and the lower limit of detection was $10 \mathrm{pg} / \mathrm{ml}$.

\section{Co-culture and transwell assay}

LN cells from mice immunized with WI (responder cells) and lymphoid cells obtained from soluble peptide treated (SPT) mice (mice receiving WI in soluble form through subcutaneous implantation of miniosmotic pumps) (SPT cells) were co-cultured with male APC in 96-well plates. Responder $\mathrm{T}$ cells number remained constant $\left(5 \times 10^{5} /\right.$ well $)$, whereas the number of SPT cells varied in the experiment reported in Fig. 1. SPT cells were used at a concentration of $5 \times 10^{5} /$ well in the experiment reported in Fig. 2. In transwell assays, responder and SPT cells were separated by a membrane ( $6.5 \mathrm{~mm}$ diameter size, $0.4 \mu \mathrm{m}$ pore size) in 24-well plates (Costar, Copenhagen, Denmark). In each well, responder cells $\left(8 \times 10^{5}\right)$ were incubated in the lower compartment with $8 \times 10^{4}$ APCs. In the upper compartment of

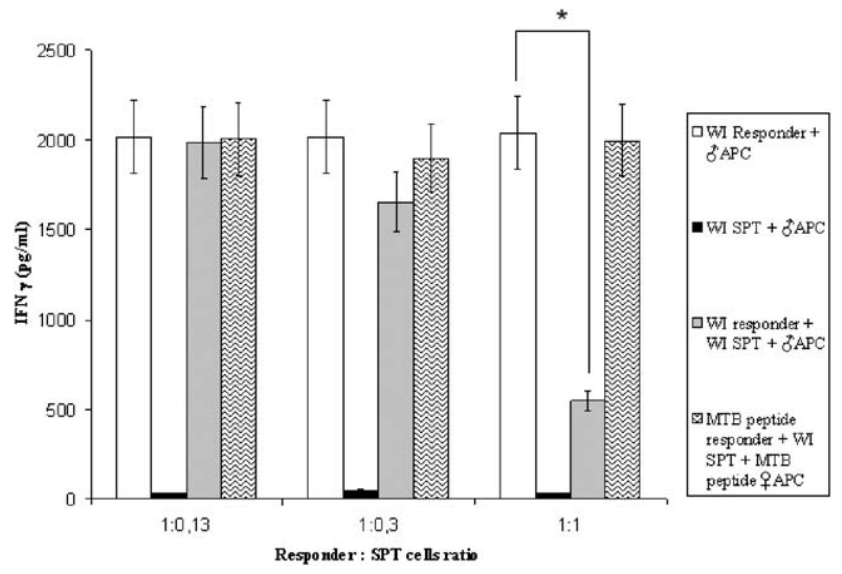

Fig. 1. Suppression of IFN- $\gamma$ production by soluble WI induced suppressor cells. IFN- $\gamma$ production by WI responder cells in co-culture with male DCs and lymphoid cells from soluble peptide treated mice (SPT cells) at various ratio was tested. As control of antigen-specific inhibition of IFN- $\gamma$ release, responder cells obtained from draining lymph node of mice immunized with $\mathrm{p} 38 \mathrm{G}$ mycobacterial peptide were exposed to p38G-pulsed DCs. Results reported are the mean of three different experiments. $* p<0.005$ when experimental group was compared to WI responder + APC.

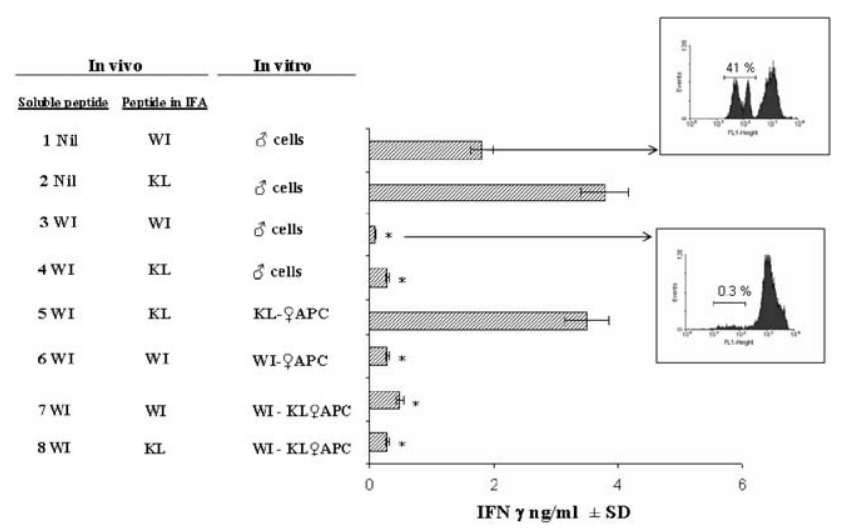

Fig. 2. WI-suppressor cells exert linked suppression. IFN- $\gamma$ levels were detected by ELISA in supernatants of co-cultures of lymphoid cells from C57BL/6 mice treated with continuous infusion of WI and lymph node cells from mice immunized with WI or KL peptides dissolved in IFA and male APCs or female APCs pulsed with WI, KL or both peptides. ${ }^{*} p<0.05$ when group 3 was compared to group 1 or group 4 was compared to group 2. FACS panels according to IFN- $\gamma$ production show cell proliferation when IFN- $\gamma$ is produced.

each well, suppressor cells were incubated at $8 \times 10^{5}$. Co-culture experiments were performed under the same conditions without separation membrane. After $48 \mathrm{~h}$, supernatants were tested for IFN- $\gamma$ production. In experiments reported in Figs. 2 and 3 responder cells were labelled with 5,6-carboxy-2,7-dechlorofluorescein (CFSE) using Oehen's method (Oehen et al. 1997) to 


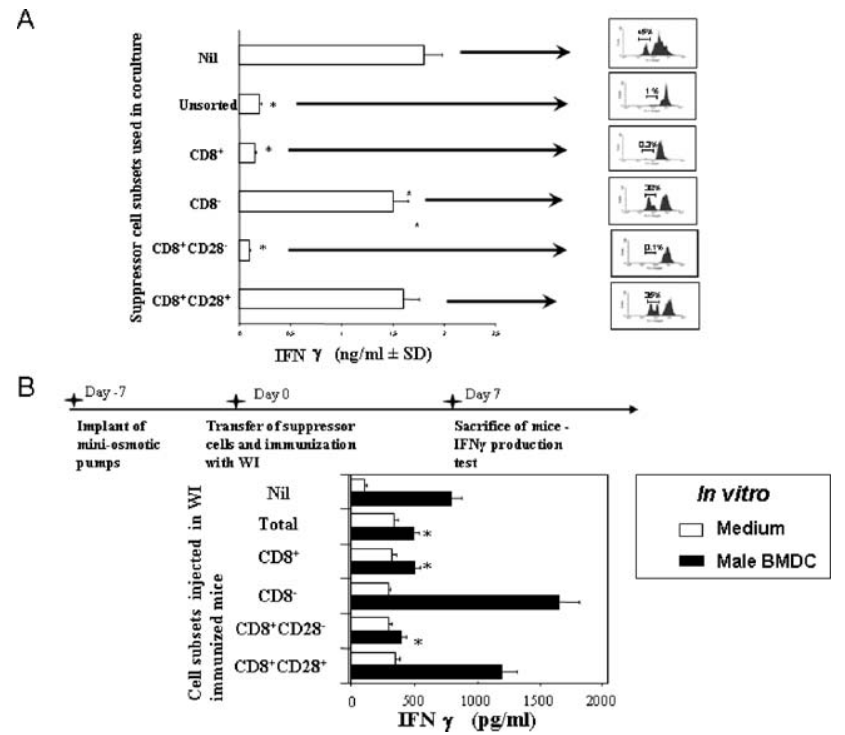

Fig. 3. In vitro and in vivo characterization of suppressor cells phenotype. Panel A. Lymphoid cells from mice treated with continuous infusion of WI were immunomagnetically separated in $\mathrm{CD}^{+}, \mathrm{CD}^{-}, \mathrm{CD} 8^{+} \mathrm{CD} 28^{+}$and $\mathrm{CD} 8{ }^{+} \mathrm{CD} 28^{-}$. Purification of each fraction was checked by FACS analysis. An equivalent number of each cell subset was co-cultured with WI responder T cells $\left(5 \times 10^{5} /\right.$ well $)$ and male APC $\left(5 \times 10^{4} /\right.$ well). The equivalent numbers of suppressor cells were: $1 \times 10^{5}$ of $\mathrm{CD}^{+}, 4 \times 10^{5}$ of $\mathrm{CD}^{-}, 5 \times 10^{4}$ of $\mathrm{CD} 8^{+} \mathrm{CD} 28^{+}$and $5 \times 10^{4}$ of $\mathrm{CD}^{+} \mathrm{CD} 28^{-}$per well. After $48 \mathrm{~h}$ of culture, supernatants were collected and IFN- $\gamma$ production was tested by ELISA. Data reported in the figure were reproduced in three different experiments without any significant differences. ${ }^{*} p<0.001$ when data obtained by co-cultures containing unsorted, $\mathrm{CD}^{+}$and $\mathrm{CD} 8^{+} \mathrm{CD} 28^{-}$suppressor cells were compared with data obtained from co-cultures containing $\mathrm{CD} 8^{-}, \mathrm{CD} 8{ }^{+} \mathrm{CD} 28^{+}$or medium. WI responder $\mathrm{T}$ cells were labelled with CFSE and exposed to antigen in the presence of various fractions of suppressor cells. A morphological gate was done on responder cells to study CFSE incorporating cells in responder $\mathrm{T}$ cells excluding propidium iodide positive cells. Panel B $1 \times 10^{8}$ of unseparated, $8 \times 10^{7}$ of $\mathrm{CD}^{-}, 1 \times 10^{7}$ of $\mathrm{CD} 8^{+}, 5 \times 10^{6}$ of $\mathrm{CD}^{+} \mathrm{CD} 28^{+}$cells and $5 \times 10^{6}$ of $\mathrm{CD} 8^{+} \mathrm{CD} 28^{-}$cells/mouse from animals treated with continuous infusion of WI, were resuspended in $0.5 \mathrm{ml}$ of RPMI and injected intraperitoneally in naive female mice that were immunized after $4 \mathrm{~h}$ by a single subcutaneous injection of WI peptide in IFA. The lymph node cells, obtained after 7 days after immunization, were cultured with irradiated male APC. IFN- $\gamma$ levels were measured using ELISA method previously reported. The same experiment was repeated three times and no significant differences were obtained. ${ }^{*} p<0.005$.

detect dividing cells in cultures incubated with or without suppressor cells.

\section{Cell separation}

Lymphoid cells from tolerized mice were separated in CD8 positive and negative fractions incubating the cells with anti-mouse $\mathrm{CD} 8 \alpha$ microbeads (Ly5, Miltenyi, Copenhagen, Denmark) and then separated in CD8 ${ }^{+}$ and $\mathrm{CD} 8^{-}$fractions according to manufacturer. To obtain $\mathrm{CD} 8^{+} \mathrm{CD} 28^{+}$or $\mathrm{CD} 8^{+} \mathrm{CD} 28^{-}$fractions the following procedures were used. The lymphoid cells were incubated with CD28-FITC-conjugate $\mathrm{mAb}$ (Clone MCA1363, Hamster IgG, Cedarlane, UK) for $15 \mathrm{~min}$ at $4{ }^{\circ} \mathrm{C}$. After washings to remove the unbound $\mathrm{mAb}$, anti-FITC multisort microbeads (Miltenyi, Copenhagen, Denmark) were added for $10 \mathrm{~min}$ at $4{ }^{\circ} \mathrm{C}$. After washings, cells were separated in $\mathrm{CD} 28^{+}$or $\mathrm{CD} 28^{-}$fractions according to manufacturer. $\mathrm{CD} 28^{-}$ fraction was collected and then processed for CD8 separation. To obtain $\mathrm{CD} 8{ }^{+} \mathrm{CD} 28^{+}$fraction Multisort kit was used to remove the beads. Then cells were separated for CD8 as described above. Recovery percentage $(>95 \%)$ was checked to FACS using antimouse CD8 $\alpha$-PECy5 YTS169.4, rat IgG2b from (BD Biosciences), after Trypan blue dye exclusion vitality test. To study down-regulation of co-stimulatory molecules expressed on surface of dendritic cells, only positive fraction of immunomagnetically sorted cells using anti-CD11c (Clone N418, hamster IgG) microbeads (Miltenyi) was analyzed.

\section{Flow cytometry}

$\mathrm{CD} 8{ }^{+} \mathrm{CD} 28^{-}$and $\mathrm{CD} 8{ }^{+} \mathrm{CD} 28^{+}$cells from untreated or WI SPT mice $\left(10^{6}\right.$ in $100 \mu \mathrm{l}$ PBS with $1 \%$ heatinactivated $\mathrm{FCS}$ and $0.02 \%$ sodium azide) were incubated with FcBlock (Clone FCR4G8, rat IgG2b, BD Biosciences). Stainings were assessed to compare surface or intracellular markers FITC-labelled described in this paragraph. $\mathrm{CD} 8^{+} \mathrm{CD} 28^{-}$and $\mathrm{CD} 8{ }^{+} \mathrm{CD} 28^{+}$ were incubated with anti-CD62L-FITC (MEL-14, rat $\mathrm{IgG} 2_{\mathrm{a}}$, BD Biosciences). As isotype control for comparison of these surface marker expression between $\mathrm{CD} 8{ }^{+} \mathrm{CD} 28^{+}$and $\mathrm{CD} 8{ }^{+} \mathrm{CD} 28^{-}$, FITC-labelled-rat $\mathrm{IgG} 2 \mathrm{a}$ (BD Biosciences) were used (data not shown). To detect FOXP3 in $\mathrm{CD} 8{ }^{+} \mathrm{CD} 28^{-}$and $\mathrm{CD} 8{ }^{+} \mathrm{CD} 28^{+}$ cells subset mouse regulatory $\mathrm{T}$ Cell, Staining Kit (eBioscience, Boston, MA, USA) with FITC-labelledmurine FOXP3 mAb (FJK16-s, rat IgG2 ${ }_{b}$, eBioscience) was used according to manufacturer.

Before cytofluorimetric analysis dendritic cells was separated using CD11c microbeads (Miltenyi). CD11c positive cells were stained with CD80-FITC mAb (Clone RMMP-1, rat IgG2 ${ }_{\mathrm{a}}$, Serotec) or with CD86-FITC mAb (Clone MCA 1587, rat IgG2 $2_{a}$, Serotec). Controls included cells stained with FITC-labelled rat $\operatorname{IgG} 2_{\mathrm{a}}$ (Serotec).

$1 \times 10^{5}$ cells were analysed gating them by FSC versus SSC using FACSCALIBUR and CELLQUEST software. Every staining experiment was repeated three times with high reproducibility of FACS analysis. 


\section{CFSE labelling}

Cells were resuspended at a density of $2 \times 10^{7} / \mathrm{ml}$ in RPMI. An equal volume of $5 \mu \mathrm{M}$ of CFSE (Molecular Probes, Inc. Eugene, OR) in RPMI was added and the cells were cultured at $37^{\circ} \mathrm{C}$ for $5 \mathrm{~min}$. The reaction was quenched by the addition of an equal volume of heat inactivated FCS. Labelled cells were washed twice with cold RPMI plus $10 \%$ heat inactivated FCS and cultured as described in the paragraph of IFN- $\gamma$ production. A morphological gate was set up excluding cells incorporating propidium iodide.

\section{Skin grafting}

Female mice were transplanted on the tail with skin grafts obtained from the tail of naïve male or female as control. The skin grafts were protected with a 4.5 -cm-long glass pipe, which was kept on the tail for 7 days. Mice were kept in individual cages with high-tech artificial bedding (Omega-Dri) instead of normal sawdust. Graft survival was followed by daily visual inspection. Scoring was performed by comparison with syngeneic control grafts and was based on redness, crust-forming and the presence of hairs. Grafts were scored as rejected when they were fully necrotic or fallen off. Positive controls received cells from mice treated with PBS.

Recipient mice were injected the same day of transplant with the following numbers of cells separated by soluble WI-treated female mice: $2 \times 10^{7}$ of $\mathrm{CD} 8^{+}$ $\mathrm{CD} 28^{-}, 2 \times 10^{7}$ of $\mathrm{CD} 8^{+} \mathrm{CD} 28^{+}, 2 \times 10^{7}$ of $\mathrm{CD} 8^{+}$and $5 \times 10^{7}$ of $\mathrm{CD}^{-}$. Cells resuspended in $0.5 \mathrm{ml}$ of RPMI plus $10 \%$ FCS, were injected i.p. in each recipient. Timing of injection and dose of cells were chosen after several experiments as the best schedule to obtain maximal inhibition of skin graft rejection.

\section{Statistics}

The double Student's $t$ test was used to compare statistical significance from experimental and control groups. Comparative analysis of skin graft survival was accomplished via the Kaplan-Meier cumulative survival method and survival differences between two groups were determined using the log-rank (Mantel-Cox) test.

\section{Results}

Continuous infusion of $1 \mathbf{~ m g}$ of WI peptide was able to delay male skin graft rejection inducing a suppressor $T$ cell subset

C57BL $/ 6$ female mice treated with $0.5 \mathrm{mg}$ of soluble peptide show a weak delay in male skin graft rejection
(42 \pm 2 days), while mice treated with $1 \mathrm{mg}$ of WI show a prolonged graft survival (more than 90 days) when compared to control mice receiving PBS alone $(30 \pm 2$ days) (data not shown). These data indicate that the higher dose of soluble immunodominant HY-D ${ }^{\mathrm{b}}$ epitope induced a delay of male skin graft rejection.

To test if the delayed rejection could be related to the induction of suppressor cells, LN cells from WIimmunized C57BL/6 mice (WI-responders) were reexposed to male DCs in presence of different amounts of lymphoid cells obtained from mice treated with continuous infusion of $1 \mathrm{mg}$ WI-peptide. Positive controls were obtained culturing responder $\mathrm{T}$ cells with male DCs while negative controls were obtained exposing SPT cells to male APCs. After $48 \mathrm{~h}$, co-cultures supernatants were tested for IFN- $\gamma$ production. Under these experimental conditions (Fig. 1) inhibition of IFN- $\gamma$ production depends on the number of SPT cells. A strong inhibition of IFN- $\gamma$ production was detected at a 1:1 ratio (responder: SPT cells). The antigen-specificity of IFN- $\gamma$ inhibition was demonstrated using cells from mice immunized with peptide derived from $38 \mathrm{Kd}$ protein of M. tuberculosis as responder cells stimulated with female DC pulsed with the mycobacterial peptide in the presence of various amounts of WI-SPT cells. No inhibition of IFN- $\gamma$ release was detected with different amounts of WI-SPT cells.

The ability of WI-specific SPT cells to inhibit IFN- $\gamma$ release not only by WI- but also by KL-responder cells was demonstrated when both WI and KL peptides were simultaneously present on the same APC, as it happens when APCs were obtained from male C57BL/6 or female pulsed with both HY peptides (Fig. 2). No inhibition of IFN- $\gamma$ release was detected when WI-SPT cells were co-cultured with KL-responder and female APCs pulsed with KL peptide (Fig. 2, line 5). Inhibition of IFN- $\gamma$ production was detected when as stimulator cells we used DCs from female mice pulsed with WI or both HY peptides. To investigate the correlation between IFN- $\gamma$ production and responder cells proliferation, $\mathrm{LN}$ cells from WI-immunized mice labelled with CFSE were exposed in vitro to antigen alone (male APCs) (Fig. 2, line 1) or in presence of WI-suppressor cells (Fig. 2, line 3). FACS panels in Fig. 3 show that WI-immune cells without SPT cells proliferated, as the related panel show that $41 \%$ of cells exhibited cellular division. In the presence of SPT cells, WI-responder cells were not able to proliferate $(0.3 \%)$.

\section{WI in soluble form induces $\mathrm{CD8}^{+} \mathrm{CD}^{-} 8^{-}$suppressor cells and transfer suppression in naive mice}

We further investigated the phenotype of antigen-specific (SPT) suppressor cells. Immunomagnetically separated $\mathrm{CD} 8^{+}, \mathrm{CD} 8^{-}, \mathrm{CD} 8^{+} \mathrm{CD} 28^{-}$and $\mathrm{CD} 8^{+} \mathrm{CD} 28^{+}$subset 
from WI-SPT cells from female mice, were co-cultured with LN cells from WI-immunized female mice and re-exposed to male naïve APCs. As shown in Fig. 3A, a lack of IFN- $\gamma$ production was evident in co-cultures containing unseparated, $\mathrm{CD} 8^{+}$and $\mathrm{CD} 8^{+} \mathrm{CD} 28^{-}$suppressor cells whereas $\mathrm{CD} 8^{-}$as well as $\mathrm{CD} 8{ }^{+} \mathrm{CD} 28^{+}$fractions failed to exert any inhibitory effect on IFN $-\gamma$ release. FACS panels shows data obtained with responder cells CFSE-labelled exposed to various cell subsets. Responder cells secreting low IFN- $\gamma$ levels display a CFSE-profile of quiescent cells with poor percentages of dividing cells.

To test if $\mathrm{CD} 8^{+} \mathrm{CD} 28^{-}$cells are able to transfer HYspecific inhibition of IFN- $\gamma$ release, different cell fractions obtained from mice treated with continuous infusion of WI were injected in naive female mice that were then immunized with WI peptide in IFA. LN cells collected from these mice were used to secrete IFN- $\gamma$ production upon in vitro antigen re-exposure, using APCs from male mice (experimental procedure summarized in the upper side of Fig. 3B).

Fig. 3B shows that $\mathrm{LN}$ cells collected from mice injected with $\mathrm{CD} 8^{+}$or $\mathrm{CD} 8^{+} \mathrm{CD} 28^{-}$suppressor cells and immunized with WI peptide, failed to produce IFN$\gamma$ when re-exposed in vitro to male APCs. Conversely, lymphocytes collected from mice injected with $\mathrm{CD} 8^{-}$ and $\mathrm{CD} 8{ }^{+} \mathrm{CD} 28^{+}$cell subset were able to produce IFN$\gamma$. This observation states that $\mathrm{CD} 8^{+}$and $\mathrm{CD} 8^{+} \mathrm{CD} 28^{-}$ suppressor cells are able to transfer hyporesponsiveness to $\mathrm{HY}-\mathrm{D}^{\mathrm{b}}$ antigens in naive animals.

The ability of WI-suppressor cells to inhibit male skin graft rejection was shown by the experiments summarized in Fig. 4. Female C57BL/6 grafted with syngeneic male skin received unseparated or separated suppressor cells. Cell fractions were injected in naive recipients at the same day of skin transplant. Fig. 4 shows that, as expected, $\mathrm{CD} 8^{-}$and $\mathrm{CD} 8^{+} \mathrm{CD} 28^{+}$do not modify appreciably the time course of rejection. About $20 \%$ of recipients injected with $\mathrm{CD} 8{ }^{+}$do not reject male skin, while $50 \%$ of recipients injected at day 0 with $\mathrm{CD} 8{ }^{+} \mathrm{CD} 28^{-}$cells display a prolonged male graft survival during the period of observation.

\section{Mechanisms of suppression exerted by $\mathrm{CD8}^{+} \mathrm{CD}^{-} 8^{-}$}

To study the involvement of APCs in suppression after 1 day of co-culture of APCs with suppressor cells APCs were tested for their ability to stimulate LN cells from WI-immune mice. APCs exposed to suppressor cells failed to stimulate IFN- $\gamma$ production by WI responder cells. Conversely, APCs co-cultured with $\mathrm{CD} 8{ }^{+} \mathrm{CD} 28^{+}$obtained from mice treated with WI in soluble form were still fully able to induce IFN- $\gamma$ production by WI-immunized LN cells (Fig. 5A).

Transwell experiments were performed to verify if the mechanism of inhibition of antigen presentation by

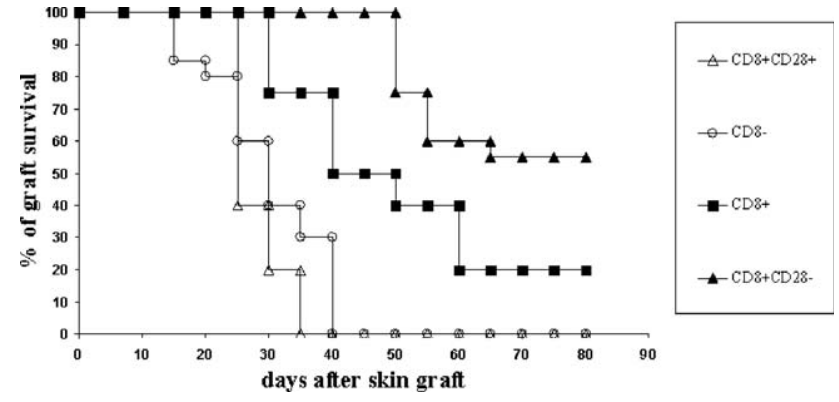

Fig. 4. $\mathrm{CD} 8^{+} \mathrm{CD} 28^{-}$regulatory cells transfer suppression to $\mathrm{HY}$ in naive mice. Soluble WI-induced $\mathrm{CD}^{+}(\mathbf{a}), \mathrm{CD}^{-}$ $(\bigcirc), \mathrm{CD}^{+} \mathrm{CD}^{-} 8^{-}(\mathbf{\Delta})$ and $\mathrm{CD} 8{ }^{+} \mathrm{CD} 28^{+}(\triangle)$ cells, resuspended in $0.5 \mathrm{ml}$ of RPMI, were injected i.p. in female C57BL/ 6 mice (10 for each experimental group) at the same day of transplant. The numbers of the cells injected are the same reported in the legend to Fig. 3B. The results reported were reproduced three times without any significant differences. The graft survival of recipients receiving $\mathrm{CD} 8^{+} \mathrm{CD} 28^{-}$cells was significantly prolonged if compared with female $\mathrm{B} 6$ recipients treated with $\mathrm{CD} 8{ }^{+} \mathrm{CD} 28^{+}$cells (log-rank test, $p<0.005$ ).

suppressor cells could be mediated by cell-cell contact or by release of "suppressive" cytokines. As shown in Fig. 5B, no appreciable suppressive effect was detected when suppressor cells were cultured separately with responder cells and APCs, suggesting a lack of involvement of suppressive cytokines. Thus, suppressor cells inhibit antigen presenting cells through cell to cell contact.

\section{T suppressor cells overexpressed CD62 $\mathrm{L}$ and FOXP3 and downregulated B7 molecules on APC}

Many markers of regulatory/suppressor cells were identified (Jiang et al. 2006): intracellular FOXP3 and surface CD62L were the more commonly identified. An analysis of the expression of CD62 ligand and FOXP3 was done comparing the expression of these markers by FACS analysis in $\mathrm{CD} 8^{+} \mathrm{CD} 28^{+}$and $\mathrm{CD} 8^{+} \mathrm{CD} 28^{-}$ obtained from untreated mice (Fig. 6A) with cells obtained from mice treated with continuous infusion of WI (Fig. 6B). To this end, $\mathrm{CD} 8^{+}$were immunomagnetically separated from WI mini-osmotic pump treated and untreated mice and then stained for CD 8 versus CD28, CD62L versus CD28 and FOXP3 versus CD28. We detected higher expression of CD62L and FOXP3 (53.4\% and $20.3 \%$ versus $2.1 \%$ and $3.4 \%$ in untreated mice, respectively) in $\mathrm{CD} 8{ }^{+} \mathrm{CD} 28^{-}$cells obtained by WI continuous infusion. After co-culture with $\mathrm{CD} 8{ }^{+} \mathrm{CD} 28^{-}$suppressor $\mathrm{T}$ cells or $\mathrm{CD} 8^{+} \mathrm{CD} 28^{+}$cells, B7 molecules expression on DC, purified as positive fraction using anti-CD11c microbeads, was analyzed. The results described in Fig. 6C show that expression of CD80 and CD86 decreased when DC were co-cultured with $\mathrm{CD} 8{ }^{+} \mathrm{CD} 28^{-}$(peaks 3 compared to peaks 1 that 


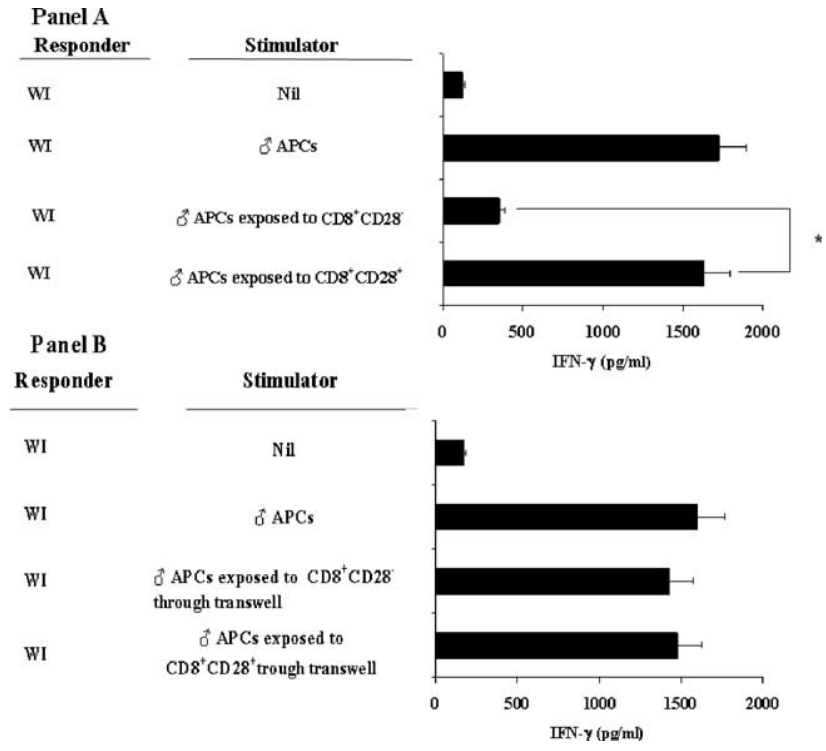

Fig. 5. $\mathrm{CD} 8{ }^{+} \mathrm{CD} 28^{-}$impair antigen presentation through cell to cell contact. (Panel A). IFN- $\gamma$ contents, detected by ELISA from WI responder cells and male APCs, exposed to $\mathrm{CD} 8{ }^{+} \mathrm{CD} 28^{-}$or $\mathrm{CD} 8{ }^{+} \mathrm{CD} 28^{+}$cells from C57BL/6 WI mini osmotic pump treated at the same cellular concentration reported in Fig. 3, were shown. ${ }^{*} p<0.005$ when data obtained pre-exposing APC to $\mathrm{CD} 8{ }^{+} \mathrm{CD} 28^{-}$were compared to preexposure to $\mathrm{CD} 8{ }^{+} \mathrm{CD} 28^{+}$cells. Data reported are the means of three different experiments. (Panel B). IFN- $\gamma$ production detected by ELISA in trans-well plate of male APC and responder cells from WI-immunized mice (upper part of the well), exposed to $\mathrm{CD} 8^{+} \mathrm{CD} 28^{-}$or $\mathrm{CD} 8^{+} \mathrm{CD} 28^{+}$cells from C57BL/6 WI mini osmotic pump treated mice (lower part of the well). Data reported are the means of three different experiments.

are mature DC alone). A weak down-regulation of CD80 and CD86 was detected also in DC exposed to $\mathrm{CD} 8{ }^{+} \mathrm{CD} 28^{+}$(peaks 2 versus peaks 1 ), probably due to a physiologic engagement of B7 molecules by CD28. These data suggest a possible mechanism of failure of antigen presentation exerted by $\mathrm{CD} 8^{+} \mathrm{CD} 28^{-}$cells on the HY-specific immune response.

\section{Discussion}

In this paper we analyzed the suppression of the immune response to minor $\mathrm{H}$ Ags induced by a continuous administration of an immunodominant $\mathrm{HY}$ peptide in soluble form. Male skin graft survival was significantly prolonged when recipient female mice were treated with $1 \mathrm{mg}$ but not with $0.5 \mathrm{mg}$ of soluble WI before male skin transplantation (data not shown).

Data shown in Fig. 1 demonstrate that the continuous delivery of soluble WI peptide is able to induce antigenspecific suppressor cells. Lymphoid cells from soluble

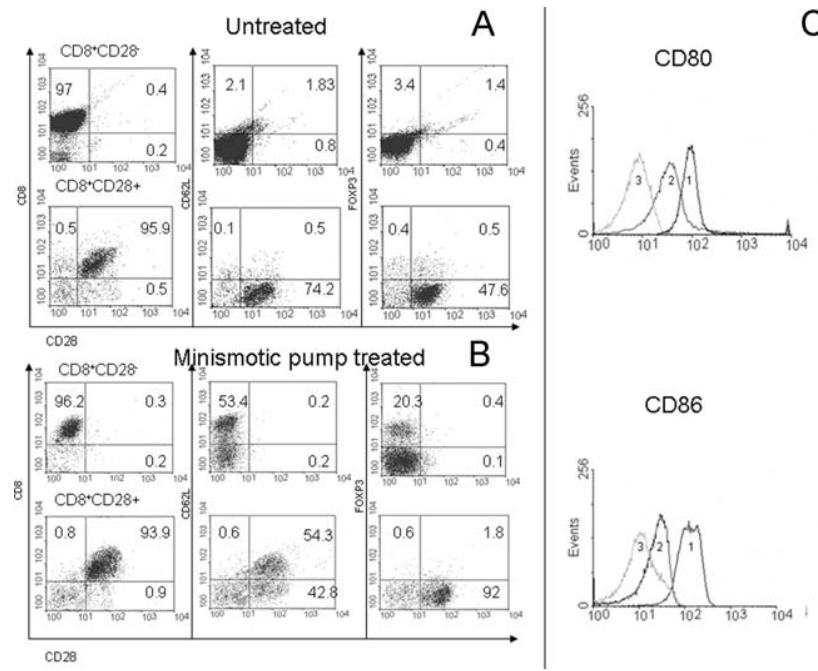

Fig. 6. $\mathrm{CD} 8{ }^{+} \mathrm{CD} 28^{-}$cells expression of CD62L and FOXP3. Suppressor cells downregulate CD80 and CD86 on DC. CD8 ${ }^{+}$ purified from lymphoid cells of WI mini-osmotic pump treated (Panel B) or naïve mice (Panel A) were stained with antiCD8, antiCD28, antiCD62 ligand or antiFOXP3. Results reported were obtained by analyzing with FACSCALIBUR living cells gated by a morphological gate excluding propidium iodide positive cells. Results reported were reproduced without any significant differences in three experiments. (Panel C) Mature dendritic cells were exposed to $\mathrm{CD} 8{ }^{+} \mathrm{CD} 28^{-}$(Peaks 3) or to $\mathrm{CD} 8{ }^{+} \mathrm{CD} 28^{+}$(Peaks 2) or to medium (Peaks 1) for $24 \mathrm{~h}$ at the same ratio reported in the legend to Fig. 3. DC were immunomagnetically separated by anti-CD11c microbeads (Miltenyi, Copenhagen, Denmark) and stained with antiCD80 or antiCD86. Similar results to the overlays showed were obtained in three different experiments gating live cells by a morphological gate excluding propidium iodide positive cells.

WI treated mice inhibit IFN- $\gamma$ release when co-cultured with responder $\mathrm{T}$ cells stimulated in vitro with the same antigen.

In our model suppressor cells exert linked suppression (Fig. 2) as they inhibit IFN- $\gamma$ release also when male DCs were used as stimulators. According to these data, the intranasal administration of WI (Chai et al. 2004) or the presentation of the same epitope by immature DCs (James et al. 2002) causes a prolonged survival of syngeneic male skin grafts. Moreover, in agreement with Davies et al. we report that induction of tolerance to a set of minor alloantigens under anti-CD4 and anti-CD8 treatment could also induce unresponsiveness to a second alloantigen when it was presented by a subsequent $F_{1}$ graft to the tolerant animal, thus leading to the concept of "linked suppression" (Davies et al. 1996).

We characterized the phenotype of the cells inhibiting in vitro the release of IFN- $\gamma$ from HY immunized cells. Only cells expressing CD8 are able to inhibit the release of IFN- $\gamma$ and this activity is restricted to $\mathrm{CD} 8^{+} \mathrm{CD} 28^{-}$ cells, as shown in Fig. 3A. This suppressor $\mathrm{T}$ cells population expresses high levels of FOXP3 (20.3\% 
versus $3.4 \%$ in untreated control mice) and $\mathrm{CD} 62 \mathrm{~L}$ $(53.4 \%$ versus $2.1 \%$ detected in untreated control animals) (Figs. 6A and B).

$\mathrm{CD} 8{ }^{+} \mathrm{CD} 28^{-}$regulatory cells have been described in different models of mice (Najafian et al. 2003; MenagerMarcq et al. 2006) and humans (Liu et al. 1998; Davila et al. 2005; Baeten et al. 2006; Manavalan et al. 2004). Relevant to our studies, increasing of $\mathrm{CD} 8^{+} \mathrm{CD} 28^{-} \mathrm{T}$ cells observed in drug-free tolerant kidney recipients (Baeten et al. 2006) suggests that the appearance of $\mathrm{CD} 8{ }^{+} \mathrm{CD} 28^{-} \mathrm{T}$ cells is a common feature in the prolonged graft survival. Our data closely resemble those obtained inducing prolonged survival of male skin by intranasal administration of peptide or immature DCs pulsed with WI (James et al. 2002; Chai et al. 2004).

It is likely that $\mathrm{T}$ suppressor cells inhibit antigen presentation, as DCs exposed to $\mathrm{CD} 8{ }^{+} \mathrm{CD} 28^{-}$fail to present antigen when used to stimulate responder cells (Fig. 5). This is a common way of action of regulatory/ suppressor cells described for alloantigen-specific suppressor $\mathrm{CD} 8{ }^{+} \mathrm{CD} 28^{-}$cells (Liu et al. 1998) and murine autoantigen-specific suppressor $\mathrm{CD} 8{ }^{+} \mathrm{CD} 28^{-}$cells $(\mathrm{Na}-$ jafian et al. 2003).

To test the ability of $\mathrm{CD} 8^{+} \mathrm{CD} 28^{-}$cells to induce prolonged $\mathrm{HY}$-incompatible graft survival, naive animals were injected with suppressor cells $\left(\mathrm{CD} 8^{+} \mathrm{CD} 28^{-}\right)$, immunized with the same peptide and then exposed to male DCs or naïve animals injected with suppressor cells were grafted with the male skin. The results reported in Fig. 3B show that the passive transfer of suppressor cells inhibits the capacity of lymphoid cells from WIimmunized animals to release IFN- $\gamma$ when in vitro reexposed to $\mathrm{HY}$ antigens and causes a significant delay of male skin graft rejection (Fig. 4).

The mechanism of action of $\mathrm{CD} 8^{+} \mathrm{CD} 28^{-}$might be due, at least in part, to the down-regulation of $\mathrm{B} 7$ molecules. This down-regulation implies that the ability of suppressor cells to transfer hyporesponsiveness to HY in naive animals is mediated by a lower efficiency of APCs to present HY epitopes to responder cells. The down-regulation of costimulatory molecules on APC may prevent efficient stimulation of $\mathrm{CD}^{+}$cells in presence of $\mathrm{CD} 8{ }^{+} \mathrm{CD} 28^{-} \mathrm{T}$ cells, leading to decreased IFN- $\gamma$ production. Since IFN- $\gamma$ is known to upregulate costimulatory molecules on APCs (Hathcock et al. 1994), it could be hypothesized that the low expression of B7 may be the consequence of the decreased production of IFN- $\gamma$.

Moreover $\mathrm{CD} 8{ }^{+} \mathrm{CD} 28^{-}$induced suppression inhibits $\mathrm{T}$ cell activation trough a cell-cell contact and is not mediated by "suppressive" cytokines (Figs. 5A and B), according to previously reported data (Najafian et al. 2003; Liu et al. 1998). It was reported (Chang et al. 2002) that $\mathrm{CD} 8^{+} \mathrm{CD} 28^{-}$alloantigen-specific suppressor $\mathrm{T}$ cells induce the up-regulation of ILT3 and ILT4 on monocytes and dendritic cells, rendering these APCs tolerogenic. We cannot exclude that this mechanism of inhibition of antigen presentation could be involved also in our model; in fact, we're currently testing if an upregulation of PIR A and PIR B (ILT3 and ILT4 equivalents in rodents) occurs in APCs exposed to $\mathrm{CD} 8{ }^{+} \mathrm{CD} 28^{-}$suppressor cells.

Several types of regulatory/suppressor T cells (Tregs) have been identified and shown to play a pivotal role in the control of autoimmunity and transplantation tolerance in rodents and in human beings (Jiang et al. 2006). Steger et al. (2006) suggest that activation of $\mathrm{CD} 4{ }^{+} \mathrm{CD} 25^{+}$regulatory $\mathrm{T}$ cells as the only phenotype involved in grafts survival could be an "oversimplification".

We propose that the suppression described here reflects a way by which suppressor $T$ cells can function as immunoregulatory cells in the maintenance and establishment of peripheral hyporesponsiveness to grafted tissues.

\section{Acknowledgments}

We thank Prof. F. Claas, Director of the Department of Immunohematology and Blood Tranfsusion, Leiden University Medical Center, accepting A. Barera for few weeks in his Department.

\section{References}

Baeten, D., Louis, S., Braud, C., Braudeau, C., Ballet, C., Moizant, F., et al., 2006. Phenotypically and functionally distinct CD8 + lymphocyte populations in long-term drugfree tolerance and chronic rejection in human kidney graft recipients. J. Am. Soc. Nephrol. 17, 294-304.

Bassiri, H., Markmann, J.F., Desai, N.M., Kim, J.I., The, H.S., Barker, C.F., 1993. Allograft rejection by T cell receptor transgenic mice. J. Surg. Res. 54, 437-444.

Chai, J.G., James, E., Dewchand, H., Simpson, E., Scott, D., 2004. Transplantation tolerance induced by intranasal administration of HY peptides. Blood 103, 3951-3959.

Chang, C.C., Ciubotariu, R., Manavalan, J.S., Yuan, J., Colovai, A.I., Piazza, F., et al., 2002. Tolerization of dendritic cells by $T_{s}$ cells: the crucial role of inhibitory receptors ILT3 and ILT4. Nat. Immunol. 3, 237-243.

Davies, J.D., Leong, L.Y., Mellor, A., Cobbold, S.P., Waldmann, H., 1996. T cell suppression in transplantation tolerance through linked recognition. J Immunol. 156, 3602-3607.

Davila, E., Kang, Y.M., Park, Y.W., Sawai, H., He, X., Pryshchep, S., et al., 2005. Cell-based immunotherapy with suppressor $\mathrm{CD}^{+} \mathrm{T}$ cells in rheumatoid arthritis. J Immunol. 174, 7292-7301.

Gavin, M.A., Dere, B., Grandea, A.G., Hogquist, K.A., Bevan, M.J., 1994. Major histocompatibility complex class I allele-specific peptide libraries: identification of peptides 
that mimic an H-Y T cell epitope. Eur. J. Immunol. 24, 2124-2133.

Greenfield, A., Scott, D., Pennisi, D., Ehrmann, I., Ellis, P., Cooper, L., et al., 1996. An H-Y D ${ }^{b}$ epitope is encoded by a novel mouse Y chromosome gene. Nat. Genet. 14, 474.

Hathcock, K.S., Laszlo, G., Pucillo, C., Linsley, P., Hodes, R.J., 1994. Comparative analysis of B7-1 and B7-2 costimulatory ligands: expression and function. J Exp Med. 180, 631.

James, E., Scott, D., Chai, J.G., Millrain, M., Chandler, P., Simpson, E., 2002. HY peptides modulate transplantation responses to skin allografts. Int. Immunol. 14, 1333.

Jiang, S., Lechler, R.I., He, X.S., Huang, J.F., 2006. Regulatory $\mathrm{T}$ cells and transplantation tolerance. Hum. Immunol. 67, 765.

Liu, Z., Tugulea, S., Cortesini, R., Suciu-Foca, N., 1998. Specific suppression of $\mathrm{T}$ helper alloreactivity by allo-MHC-class I restricted $\mathrm{CD} 8{ }^{+} \mathrm{CD} 28^{-} \mathrm{T}$ cells. Int. Immunol. 10, 775.

Manavalan, J.S., Kim-Schutze, S., Scotto, L., Naiyer, A.J., Vlad, G., Colombo, P.C., et al., 2004. Alloantigen specific $\mathrm{CD} 8{ }^{+} \mathrm{CD} 28^{-} \mathrm{FOXP}^{+} \mathrm{T}$ suppressor cells induce IL$\mathrm{T}^{+}{ }^{+} \mathrm{ILT}^{+}{ }^{+}$tolerogenic endothelial cells, inhibiting alloreactivity. Int. Immunol. 16, 1055.

Markiewicz, M.A., Girao, C., Opferman, J.T., Sun, J., Hu, Q., Agulnik, A.A., et al., 1998. Long-term T cell memory requires the surface expression of self-peptide/major histocompatibility complex molecules. Proc. Natl. Acad. Sci. USA 95, 3065.

Menager-Marcq, I., Pomie, C., Romagnioli, P., van Meerwijk, J.P., 2006. CD $8^{+} \mathrm{CD} 28^{-}$regulatory $\mathrm{T}$ lymphocytes prevent experimental inflammatory bowel disease in mice. Gastroenterology 131, 1775.
Najafian, N., Chitnis, T., Salama, A.D., Zhu, B., Benou, C., Yuan, X., et al., 2003. Regulatory functions of $\mathrm{CD} 8{ }^{+} \mathrm{CD} 28^{-} \mathrm{T}$ cells in an autoimmune disease model. $\mathrm{J}$. Clin. Invest. 112, 1037.

Oehen, S., Brduscha-Riem, K., Oxenius, A., Odermatt, B., 1997. A simple method for evaluating the rejection of grafted spleen cells by flow cytometry and tracing adoptively transferred cells by light microscopy. J. Immunol. Meth. 207, 33.

Scott, D., Addey, C., Ellis, P., James, E., Mitchell, M.J., Saut, N., et al., 2000. Dendritic cells permit identification of genes encoding MHC class II-restricted epitopes of transplantation antigens. Immunity 12, 711.

Simpson, E., Roopenian, D., 1997. Minor histocompatibility antigens. Curr. Opin. Immunol. 9, 655.

Simpson, E., Scott, D., Chandler, P., 1997. The male-specific histocompatibility antigen, H-Y: a history of transplantation, immune response genes, sex determination and expression cloning. Annu. Rev. Immunol. 15, 39.

Simpson, E., Scott, D., James, E., Lombardi, G., Cwynarski, K., Dazzi, F., et al., 2002. Minor H antigens: genes and peptides. Transpl. Immunol. 10, 115.

Sireci, G., Dieli, F., Caccamo, N., Bonanno, C.T., Salerno, A., 1999. Induction and tolerization of anti-male CD8 ${ }^{+}$ cytotoxic $\mathrm{T}$ lymphocytes by in vivo immunization with an H-Y-derived peptide. Hum. Immunol. 60, 764.

Steger, U., Kingsley, C.I., Karim, M., Bushell, A.R., Wood, K.J., 2006. CD $25^{+} \mathrm{CD}^{+}{ }^{+}$regulatory T cells develop in mice not only during spontaneous acceptance of liver allografts but also after acute allograft rejection. Transplantation 82 , 1202. 